\title{
O Profissional de Custos e as Competências Buscadas pelas Empresas em Anúncios de Emprego
}

\section{The Cost Professional and the Skills Sought by Companies in Job Advertisements}

\author{
${ }^{a}$ Centro Universitário Leonardo da Vinci. SC, Brasil. \\ ${ }^{\mathrm{b}}$ Centro Universitário da Grande Dourados. MS, Brasil. \\ 'Instituto Adventista Paranaense. PR, Brasil. \\ *E-mail: johny.hmc@gmail.com
}

Johny Henrique Magalhães Casado*a; Viviane Asanuma Paulino ${ }^{\text {; }}$ João Simba Andréc

\begin{abstract}
Resumo
A busca por desenvolver uma vantagem competitiva diante de mercados globalizados e de alta concorrência faz com que as empresas necessitem de profissionais multifacetados para o desenvolvimento das suas operações. A presente pesquisa visa apresentar quais são as principais competências buscadas pelas empresas, quando necessitam contratar profissionais para o seu setor de cursos, para atingir tal objetivo foi realizado um levantamento de sessenta e três vagas de empregos no setor de custo nos maiores sites de vagas do Brasil. Concluiu-se que o perfil do profissional de custo possui graduação em Ciências Contábeis, Administração ou Economia, também possui Pós-graduação, fala uma segunda língua, possui experiência no setor de custos e, também, domina o pacote Office da Microsoft e Softwares ERP's.
\end{abstract}

Palavras-chave: Estratégia. Competências. Perfil Profissional.

\begin{abstract}
The search to develop a competitive advantage before the globalized and high competition markets, makes companies need multifaceted professionals for the development of their operations. This research aims to present what the main competencies are sought by companies when they need to hire professionals for their courses sector; In order to achieve this objective, a survey of 63 job vacancies in the cost sector was carried out at the largest vacancy sites in Brazil. It was concluded that the cost professional profile has a degree in accounting, administration or economics, also has a graduate degree, speaks a second language, has experience in the cost sector and also dominates the Microsoft office suite and ERP's software.
\end{abstract}

Keywords: Strategy. Skills. Professional Profile.

\section{Introdução}

As organizações necessitam cada vez mais de profissionais multifacetados, que possam ocupar diferentes funções ao mesmo tempo, que sejam proativos e que tomem decisões assertivas em ambientes de muita pressão, cada vez mais competitivos e exigentes (GOMES; SOUZA, LUNKES, 2013). Considerando que "o desenvolvimento da contabilidade está estritamente relacionado às mudanças ocorridas na evolução da sociedade, repercutindo, assim, nas organizações" (CAVALCANTE; AMORIM, 2017, p.1), o profissional responsável pela atividade contábil também necessitará evoluir na busca por competências e habilidades necessárias em sua função.

Nas duas últimas décadas, dezenas de artigos têm sido produzidos com o intuito de demonstrar as competências e as habilidades do profissional contábil, entre essas pesquisas se destacam algumas produzidas em território nacional entre outras inúmeras internacionais (BERND; ANZILAGO; MACHADO, 2014; GRANLUND; TAIPALEENMAKI, 2004; HARTMANN; MASS, 2010; LAMES, ALMEIDA, 2009; REIS et al., 2014; SOUZA, BORINELLI, 2009;
ZONI; MERCHANT, 2007; ZORN, 2004; WEBER, 2011;). Considerando a multiplicidade de papéis que o profissional da contabilidade pode ocupar dentro de uma organização, a presente pesquisa concentrará sua análise naquele que está mais ligado com a estratégia da organização, sobretudo, o que engloba a gestão estratégica de custos.

O gerenciamento estratégico de custos tem ganhado espaço cada vez maior no processo decisório das organizações, ao se considerar o ambiente externo e interno como catalisadores dos processos de mudanças dentro das empresas, esse tipo de controle é um dos principais responsáveis pela geração de informações, que auxiliam na tomada de decisões e tomada de controle nas organizações (SOUZA et al, 2010; LAUSCHNER, BEUREN, 2004). A gestão estratégica na área de custos possibilita que organizações dos mais diferentes tamanhos e setores estejam preparadas para um ambiente de negócios globalizado, competitivo, hostil e não permissivo com erros e falhas (SHANK; GOVINDARAJAN, 1995; SLAVOV, 2013; SOUZA et al., 2010).

O profissional responsável pela elaboração da estratégia de custos nas organizações deverá possuir competências 
e habilidades capazes de atender às necessidades desses negócios. Para Calijuri (2011, p. 52), esse profissional deve ter "alta capacidade de trabalho e que saiba trabalhar sob pressão, além de ter fortes valores éticos, iniciativa, entusiasmo e determinação". Considerando o exposto até o momento, bem como após demonstrar a existência de pesquisas que versam sobre o perfil do profissional contábil, a presente pesquisa intenta ser um diferencial no sentido de apresentar qual o perfil, as competências e as habilidades que o profissional contábil deve possuir para trabalhar na gestão estratégica de custos, segundo a ótica das empresas.

Surge, então, a seguinte questão: qual o perfil de profissional buscado pelas empresas ao necessitarem de um profissional para trabalhar com a gestão de seus custos?

Destarte, o presente estudo teve como objetivo apresentar quais são as principais competências e habilidades que caracterizam o perfil profissional que trabalha com custos dentro das organizações brasileiras. Visando a consecução do objetivo anteriormente apresentado foram utilizadas as informações disponibilizadas nos sites de seis grandes empresas que realizam recrutamento, intermediação, cadastro e divulgação de vagas de emprego no Brasil.

A pesquisa é relevante, uma vez que pretende contribuir para a reflexão sobre as competências que as organizações buscam no processo de contratação do profissional para gerir sua estratégia de custos. Busca-se, também, apresentar, de forma clara e objetiva, quais perfis de profissionais têm encontrado aderência às vagas de emprego oferecidas durante o período de pesquisa.

Em termos estruturais, este artigo se encontra dividido em quatro seções distintas, porém que se complementam com intuito de responder o questionamento delineador da pesquisa. Na primeira seção serão apresentados os referenciais teóricos, que permitiram sustentação a essa pesquisa. A segunda seção apresentará a metodologia utilizada para a captação e tratamento dos dados que nortearam a pesquisa. A terceira seção apresentará os dados captados nos sites de anúncios de vagas, sendo analisadas as principais competências e habilidades descritas pelas empresas em seus anúncios de emprego para profissionais de custos. A quarta e última seção apresentará as conclusões obtidas com a realização desta pesquisa.

\section{Desenvolvimento}

\subsection{Metodologia}

A presente pesquisa assume uma natureza qualitativa, pois “desenvolve-se em uma situação natural, oferecendo riqueza de dados descritivos, bem como focalizando a realidade de forma complexa a contextualizada" (MARCONI; LAKATOS, 2017 , p. 303), para isso, este fará uso da “coleta de dados se medição numérica para descobrir ou aprimorar perguntas de pesquisa no processo de interpretação" (SAMPIERI; COLLADO; LUCIO, 2013, p. 33).
A presente pesquisa poderá também ser enquadrada como sendo aplicada, pois esta possui como objetivo "gerar conhecimentos para aplicação prática e dirigidos à solução de problemas específicos. Envolve verdades e interesses locais", conforme explicam Silva e Menezes (2005, p. 20). Em relação aos procedimentos técnicos, esta poderá ser classificada como descritiva, pois pretende descrever os fatos e fenômenos de determinada realidade (TRIVIÑOS, 1987).

A coleta de informações para este artigo contemplou dados secundários disponíveis nos maiores e mais visitados sites de anúncios de vagas de emprego do Brasil, conforme Quadro 1.

Quadro 1 - Sites de anúncio de vagas de empregos mais acessados no Brasil

\begin{tabular}{|l|l|c|}
\hline \multicolumn{1}{|c|}{ Organização } & \multicolumn{1}{|c|}{ Endereço Web } & $\begin{array}{c}\text { Posição no } \\
\text { Ranking } \\
\text { Brasil }\end{array}$ \\
\hline Vagas.com & https://www.vagas.com.br/ & 158 \\
\hline Infojobs & https://www.infojobs.com.br/ & 299 \\
\hline $\begin{array}{l}\text { Sine - Site } \\
\text { Nacional de } \\
\text { Empregos* }\end{array}$ & https://www.sine.com.br & 363 \\
\hline Catho & https://www.catho.com.br/ & 488 \\
\hline Empregos.com & https://www.empregos.com.br/ & 698 \\
\hline Indeed & https://www.indeed.com.br/ & 764 \\
\hline
\end{tabular}

(*) Site privado que não possui relação com o Poder Público

Fonte: Dados da pesquisa.

O recorte temporal utilizado compreendeu o período de 01 de outubro a 31 de dezembro de 2017 , no qual se obteve o total de 63 vagas anunciadas que atenderam os seguintes critérios: possuísse em seu título ou especificações o termo "custos"; apresentasse ao menos três dos seguintes critérios: nível hierárquico, formação, atribuições do cargo, conhecimentos prévios (experiência), necessidade de língua estrangeira e necessidade de pós-graduação; as vagas foram buscadas em todo território nacional.

A análise dos dados foi realizada com o intuito de estabelecer conexões, mediações e contradições dos fatos que constituem a problemática investigada (MARTINS, THEÓPHILO, 2009). Os dados foram estudados considerando a análise de conteúdo descrita por Bardin (1997) como:

Um conjunto de instrumentos metodológicos, cada vez mais sutis em constante aperfeiçoamento que se aplicam a discursos (conteúdos e continentes) extremamente diversificados. O fator comum destas técnicas múltiplas e multiplicadas desde o cálculo de frequência que fornece dados cifrados, até a extração de estruturas traduzíveis em modelos - é uma hermenêutica controlada, baseada na dedução: a inferência. Enquanto esforços de interpretação, a análise de conteúdo oscila entre dois polos do rigor da objetividade e da fecundidade da subjetividade.

O processo de busca e de catalogação dos dados para esta pesquisa se dividiu em cinco fases, como mostra o Quadro 2. 
Quadro 2 - Processo de busca e de catalogação dos dados deste estudo

\begin{tabular}{|c|l|}
\hline Fases & \multicolumn{1}{|c|}{ Procedimento } \\
\hline $1^{\text {a }} \cdot$ & $\begin{array}{l}\text { Escolha dos sites para a pesquisa - esta fase considerou } \\
\text { os sites mais bem ranqueados entre os sites de anúncios } \\
\text { de vagas de todo o Brasil. }\end{array}$ \\
\hline $2^{\mathrm{a}} \cdot$ & $\begin{array}{l}\text { Escolha das vagas - as vagas encontradas deveriam } \\
\text { possuir os critérios estipulados e já foram mencionados. }\end{array}$ \\
\hline $3^{\mathrm{a}} \cdot$ & $\begin{array}{l}\text { Coleta - registro dos dados de todas as vagas } \\
\text { encontradas e que possuíssem os critérios estipulados. }\end{array}$ \\
\hline $4^{\mathrm{a}} \cdot$ & $\begin{array}{l}\text { Catalogação dos dados - agrupamento das informações } \\
\text { semelhantes objetivando a análise. }\end{array}$ \\
\hline $5^{\mathrm{a}}$. & $\begin{array}{l}\text { Análise dos dados - fase de apresentação e análise dos } \\
\text { dados que será apresentada na próxima seção. }\end{array}$ \\
\hline
\end{tabular}

Fonte: Dados da pesquisa.

$\mathrm{Na}$ seção seguinte, além da apresentação e análise dos dados foram apresentadas as principais competências buscadas pelas empresas, quando anunciam uma vaga para o seu setor de custos.

\subsection{Estratégia organizacional e vantagem competitiva}

A gestão estratégica dentro do ambiente organizacional é assunto amplamente debatido e abordado por diversos teóricos, que se dedicam a estudar a gestão das organizações. Mesmo após ser amplamente debatido, esse tema sempre se apresenta como importante, pois o enfoque dado a cada nova pesquisa permite novas faces de um assunto inesgotável. $\mathrm{O}$ enfoque da gestão estratégica, em palavras gerais, estaria no fato de se tomar decisões privilegiando uma visão generalista não se esquecendo das inúmeras particularidades que a organização possui (JOHNSON et al., 2011).

Compreender o termo estratégia exige um conhecimento prévio dos interlocutores, porém desde a década de sessenta, o termo é amplamente empregado em diversas áreas do conhecimento e com diferentes níveis de complexidade. Necessário mencionar que o uso do termo estratégia pode encontrar diferentes nuances, quando aplicado dentro de uma organização em se comparando com o seu uso na academia (PUPO; MARTIN; 2011; BOWMAN et al., 2001).

Chakravarthy e White (2001) expõem que o processo de formulação estratégica pode ocorrer de forma diferenciada, no campo organizacional, isso ocorre, pois esse pode ser conduzido por um único indivíduo, sendo que em outras esse pode ser responsabilidade de uma equipe que proporá a estratégia a ser adotada. Salienta-se, entretanto, que a formulação da estratégia sempre está envolvida com os campos sociais, políticos e psicológicos que compõem a gestão do negócio. Mintzberg et al. (2010) apresentam dez escolas da estratégia e que contribuem para se compreender como se dá o processo de formulação estratégica em uma organização (Quadro 3).
Quadro 3 - Relação das escolas e formulação estratégica da organização

\begin{tabular}{|l|l|}
\hline \multicolumn{1}{|c|}{ Escola } & $\begin{array}{c}\text { Princípios da Formulação } \\
\text { da Estratégia }\end{array}$ \\
\hline Design & Processo de concepção \\
\hline Planejamento & Processo formal \\
\hline Posicionamento & Processo analítico \\
\hline Escola Empreendedora & Processo visionário \\
\hline Escola Cognitiva & Processo mental \\
\hline Aprendizado & Processo emergente \\
\hline Poder & Processo de negociação \\
\hline Cultural & Processo coletivo \\
\hline Ambiental & Processo reativo \\
\hline Configuração & Processo de transformação \\
\hline Fon
\end{tabular}

Fonte: Mintzberg et al. (2010).

Conhecidas como as dez escolas da estratégia, essas teorias entendem o processo de formulação da estratégia como algo particular e único. Cabe reforçar, entretanto, que apesar de diferentes essas escolas possuem similaridades de acordo com sua natureza, por exemplo, as escolas do design, do planejamento e do posicionamento são consideradas mais ortodoxas e metódicas em relação ao processo de formulação estratégica. As escolas empreendedoras, cognitiva, aprendizado, do poder, cultural e ambiental se diferenciam das demais por sua natureza descritiva e por explicitarem como as estratégias são implementadas e formuladas. Mintzberg et al. (2010) trazem como exceção a escola da configuração, pois essa pode ser caracterizada tanto como prescritiva quanto descritiva.

Classificar os processos de formulação da estratégia em escolas distintas não torna o tema uma mera escolha sobre qual é o melhor ou menos adequado em cada ocasião, cabe salientar que todos esses processos têm sua importância e contribuem, de forma diferenciada, para o estudo e compreensão do tema academicamente (CHAKRAVARTHY; WHITE, 2001). O estudo estratégia tem considerado que a melhor forma de se estudar o processo de formulação da estratégia é permitir uma síntese entre as dez escolas e não a escolha de apenas uma teoria. Ao se considerar o estudo de todas as teorias, os pesquisadores e os formuladores obterão inúmeras possibilidades e aplicabilidades sobre o tema (MINTZBERG et al., 2010; PUPO, MARTIN; 2011).

$\mathrm{O}$ ambiente propício para a formulação da estratégia ocorre quando a organização necessita responder a alguma demanda, seja essa interna ou externa, bem como quando um concorrente age prejudicando seus resultados. Geralmente, as estratégias são respostas que emanam da alta administração com o intuito de melhor posicionar a empresa diante dos percalços do mercado em que está situada (ROCHA, 1999). A estratégia para Johnson et al. (2011, p.45) pode ser considerada:

a direção e o escopo de uma organização no longo prazo, que obtém vantagem em um ambiente em mudança através de sua configuração de recursos e competências com o objetivo de atender às expectativas dos stakeholders. 
Destarte, considera a estratégia como o meio pelo qual as organizações se apresentam de forma diferenciada diante da concorrência, essas diferenciações podem ser denominadas de vantagens competitivas, conforme traz Porter (1985). O termo vantagem competitiva pode ser definida também como "a influência líquida de todos os fatores idiossincráticos da empresa sobre o seu desempenho durante um período determinado, excluídas as influências de outros fatores, como a indústria, os fatores temporais e o erro estatístico" (VASCONCELOS; BRITO, 2014, p.55). Nem todo valor criado pelas organizações pode ser apontado como uma vantagem competitiva, segundo Brito e Brito (2012), somente pode ser considerada como tal, se o cliente e o mercado compreenderem aquele diferencial como um valor efetivo e exclusivo da empresa.

$O$ processo de alcance de uma vantagem competitiva por uma organização pode ocorrer ao se adotarem diversas estratégias, Beuren e Schaeffer (1997) trazem que as principais são liderança de custo, diferenciação e estoque. A integração dos mercados internacionais, em função de globalização e o aumento da concorrência com empresas globais, tem ocasionado uma busca frenética por parte das organizações pelo binômio baixo-custo e alta qualidade (LAUSCHNER; BEUREN, 2004; ALENCAR; GUERREIRO, 2003). Desbravar o ambiente de negócios, encontrando pontos em que seja possível diferenciar dos concorrentes através das vantagens competitivas é tarefa do gestor e formulador da estratégia dentro das organizações. A gestão estratégica de custos é condição sine qua non na busca por vantagens competitivas no Mundo globalizado.

\subsection{Gestão Estratégica de Custos}

Gerenciar os custos em uma organização, de forma estratégica, envolve muito do simplesmente buscar o menor custo, o profissional responsável deve também considerar os impactos de suas decisões no ambiente externo e interno, em que a organização está inserida, bem como buscar maior assertividade no processo de tomada de decisão (SOUZA et al., 2010). Recentes mudanças ocorridas nos sistemas de contabilidade gerencial elevaram a gestão estratégica de custos (GEC), a condição de catalisadora de vantagens competitivas para a organização (LAUSCHNER; BEUREN, 2004).

Shank (1989) define a GEC como parte integrante do processo de gestão dos negócios, que se divide em quatro etapas distintas: a) formulação de estratégia; b) comunicação dessa estratégia para toda organização; c) desenvolvimento e implementação de táticas para implantação da estratégia; e) desenvolvimento e implementação de controle dessas estratégias.

A GEC possibilita integrar a gestão de custos aos objetivos estratégicos da organização (SHANK; GOVINDARAJAN, 1995), com isso, as decisões são tomadas considerando a competitividade do setor e objetivando as melhores condições para que a organização crie valor para seus clientes. Os processos organizacionais na área de custos devem estar alinhados, pois esses compõem a estratégia global de qualquer organização (WITTMANN et al., 2012).

Quesado e Rodrigues (2007) apontam que a GEC permite analisar os processos em que há agregação de valor por parte da empresa e a cadeia de produção como um todo. Complementando, ainda, o exposto, López e Ibarra (1996, p. 319) afirmam que:

para que uma organização tenha êxito competitivo, os seus custos devem estar em consonância com os das empresas rivais. Só se poderia justificar a disparidade de custos quando os produtos e serviços das entidades concorrentes são diferenciados.

\section{Slavov (2013, p. 247) traz que:}

uma das características da GEC [...] é o seu elemento de imprevisibilidade e, portanto, de risco. A GEC envolve decisões que afetam toda a organização, em condições de incerteza considerável. O resultado de tais decisões pode ser o fracasso do negócio.

Segundo Guilding, Cravens e Tayles (2000), as práticas da GEC podem ser descritas por: a) sejam orientadas para o mercado ou o ambiente externo da organização; b) tenham como foco a concorrência; c) A orientação temporal seja sempre o longo prazo.

Souza, Silva e Pilz (2010, p.162) afirmam que apesar de toda ênfase da literatura quanto às necessidades de adoção das práticas de GEC, ainda há muito a evoluir em sua validação e utilização pelas empresas. Entende-se que há um "descolamento" entre as perspectivas da GEC no ambiente de negócios e com o disposto na academia se faz necessário, então, apresentar os conceitos de competências e de habilidades profissionais para que se possa considerar qual o perfil de profissionais buscados pelas organizações para trabalhar na gestão estratégica de custos.

\subsection{Competências profissionais: definição}

McClelland (1973) auxiliou com sua obra a introduzir o conceito de competência entre administradores e psicólogos, a definição amplamente aceita, dita que competência é uma característica inerente a uma pessoa e que pode ocasionar um desempenho superior em uma determinada tarefa ou situação.

A despeito do uso do termo competência ter ganho popularidade nos anos setenta, nos Estados Unidos, somente após vinte anos é que surgem modelos de aplicação para a gestão de pessoas no ambiente organizacional, o conceito de competência passa a ser utilizado então como um parâmetro para a construção de instrumentos de gestão (NAKATA; SOUSA, 2012). Fleury (2002, p. 55) define competência como um:

saber como agir com responsabilidade e autenticidade; e implica também mobilizar, integrar, transferir conhecimento, recursos e habilidades que agreguem valor econômico ao organização e valor social para o indivíduo.

Desde a década de 1990, o modelo de competências para gestão de pessoas se tornou um dos mais difundidos e estudados, sendo que a maioria das pesquisas realizadas 
foram baseadas em resultados organizacionais (ROCHA; PASSADOR; SHINYASHIKI, 2017). Segundo Dutra (2017), organizações e pessoas devem estar, lado a lado, em um processo contínuo de troca de competências. Lames e Almeida (2009, p. 4) complementam que:

torna-se importante integrar as competências das pessoas com estratégias bem definidas para que dessa forma haja condições de implementá-las, tornando-a um processo de aprendizagem permanente.

O conceito de competência auxilia na caracterização e comprovação do conceito de valor, isso ocorre em função do fato de competência ser vista como uma conotação pragmática e operacional na maioria das organizações, ou seja, essas são reconhecidas como o conjunto de conhecimentos, habilidades e atitudes (BARBOSA, 2008).

De acordo com Dutra, Hipolito e Silva (2000, p.163), a "competência pode ser prevista ou estruturada, de modo que se estabeleça um conjunto qualificador ideal, para que a pessoa apresente uma realização superior em seu trabalho".

Não existe uma lista de competências do colaborador modelo, as competências podem variar dependendo do contexto e do modelo de gestão que a organização adota (BARROS; PAIVA; CAPELLE, 2017).

\subsection{Apresentação e análise dos dados}

A gestão estratégica de custos como demonstrado na teoria apresentada na seção do referencial é de suma importância para as organizações, que desejam se posicionar com vantagem perante seus concorrentes, sendo assim, a contratação de profissionais para executarem para essa área deve ser vista como algo de extrema importância para todas as organizações. No levantamento de dados realizado se constatou que, no período utilizado como recorte temporal, foram encontradas sessenta e três vagas abertas em todo o Brasil e que tinham como intenção a contratação de colaboradores para a área de custos nas organizações. Conforme o Quadro 4 pode ser observada que há uma diversidade grande entre os títulos dos cargos, que se enquadraram nos critérios desta pesquisa.

Quadro 4 - Título das vagas anunciadas X Quantidade

\begin{tabular}{|l|c|}
\hline \multicolumn{1}{|c|}{ Vaga } & Quantidade \\
\hline Analista Contábil & 3 \\
\hline Analista de Controladoria e Custos & 6 \\
\hline Analista de Custos & 32 \\
\hline Analista de Custos Orçamentários & 1 \\
\hline Analista de Custos Produtivos & 2 \\
\hline Analista de Orçamentos e Custos & 2 \\
\hline Analista de Gestão de Custos & 1 \\
\hline Assistente de Custos & 3 \\
\hline Auxiliar de Custos & 1 \\
\hline Coordenador de Custos & 4 \\
\hline Financial Cost Analyst & 2 \\
\hline Gerente de Custos & 1 \\
\hline Pricing Analyst & 2 \\
\hline Supervisor de Custos & 3 \\
\hline Total & 63 \\
\hline
\end{tabular}

Fonte: Dados da pesquisa.
Constatou-se que as empresas anunciantes das vagas possuem predileção pelo título "Analista de Custos", pois um pouco mais da metade das vagas anunciadas optaram por esse título. Necessário destacar que apesar de haver predileção por esse título, nem sempre um mesmo profissional poderia ter seu perfil considerado para mais de uma vaga, isso se explica, pois os anúncios, apesar de indicarem o mesmo título das vagas, apresentam que a mesma possuiria níveis hierárquicos diferentes. Das 32 vagas de Analista de Custos anunciadas no período: 10 eram para colaboradores em nível pleno, 21 para o nível analista e 1 para nível júnior/trainee, isso pode ser explicado, pois as empresas possuem plano de cargos diferenciados. Outra explicação é que por possuírem suas particularidades e atuarem em setores distintos as organizações definem seu organograma de acordo com suas necessidades.

Das vagas apresentadas na tabela constam 14 títulos de vagas distintos, nota-se que dois anúncios (4 vagas) são em língua inglesa, analisando detalhadamente essas vagas se nota que as mesmas são destinadas para profissionais que possuem disponibilidade para se mudarem para a cidade de Greensboro, localizada na Carolina do Norte - Estados Unidos. No Quadro 4 constam as informações do site do Ministério do Trabalho, em que consta registrada a CBO - Classificação Brasileira de Ocupações, quando se busca pelo termo "custo", aqui são 5 ocupações, sendo: duas destinadas aos formados em contabilidade, um para o técnico em contabilidade, um para professor de contabilidade, porém a última ocupação é destinada aos formados no curso Técnico em Construção Civil.

Quadro 5 - CBO das ocupações relacionadas aos custos

\begin{tabular}{|l|c|c|}
\hline \multicolumn{1}{|c|}{ Título da Vaga } & CBO & Função Principal \\
\hline Analista de custos & $2522-10$ & Contadores e afins \\
\hline $\begin{array}{l}\text { Assistente de contador } \\
\text { de custos }\end{array}$ & $2522-10$ & Contadores e afins \\
\hline Auxiliar de custos & $4131-10$ & $\begin{array}{c}\text { Auxiliares de } \\
\text { contabilidade }\end{array}$ \\
\hline $\begin{array}{l}\text { Professor de análise de } \\
\text { custos }\end{array}$ & $2348-15$ & $\begin{array}{c}\text { Professor de } \\
\text { contabilidade }\end{array}$ \\
\hline $\begin{array}{l}\text { Técnico de analista de } \\
\text { custos (construção civil) }\end{array}$ & $3121-05$ & $\begin{array}{c}\text { Técnicos em construção } \\
\text { civil (edificações) }\end{array}$ \\
\hline
\end{tabular}
Fonte: dados da pesquisa.

Segundos os dados levantados das sessenta e duas vagas ofertadas no período, $42(67,7 \%)$ solicitaram dos profissionais que os mesmos tivessem formação em Ciências Contábeis, essa informação pode ser observada na Figura 1. As carreiras de Administração, de Economia e de Engenharia também aparecem como demandadas para essas funções, vinte anúncios não informam se há a necessidade de alguma escolaridade para a função, enquanto apenas uma exige como pré-condição o Ensino Médio. 
Figura 1 - Formação demandada pelas empresas nos anúncios

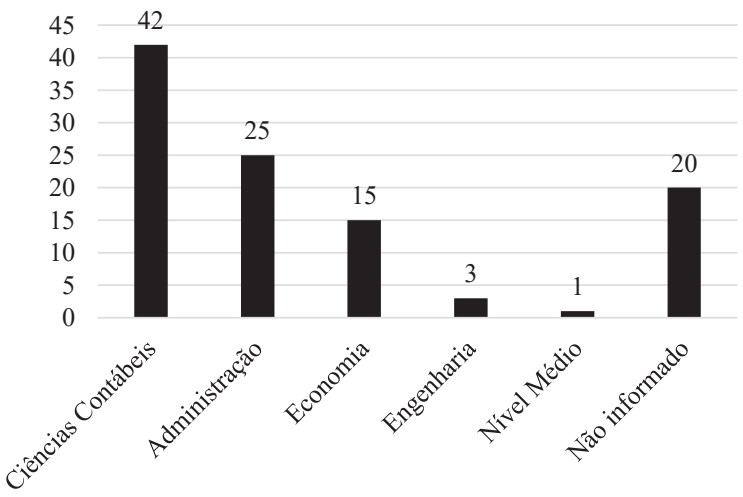

Fonte: Dados da pesquisa.

Ainda, em relação à Figura 1, necessário apontar que algumas empresas optam por aceitar a inscrição nas vagas de formados em diferentes graduações, ou seja, essa apresenta como requisito de contratação tanto formados em Ciências Contábeis, quanto graduados em Administração, Economia ou Engenharia. Em relação à Pós-graduação apenas três anúncios mencionam a necessidade de o profissional ser pósgraduado, porém não explicitam qual seria o curso desejado. Sobre a necessidade de possuir língua estrangeira se tem que em relação aos profissionais falarem uma segunda língua, apesar de 48 anúncios não terem a língua estrangeira como requisito, 15 anúncios que totalizam $23,8 \%$ do total, estipulam esse pré-requisito para as vagas anunciadas.

A Figura 2 expõe uma nuvem de palavras composta pelos termos mais utilizados na descrição das atribuições do cargo e se percebe que há prevalência pelo "fazer" em relação às atividades, ou seja, as vagas divulgadas versam, principalmente, cargos nos quais o colaborador realizará a gestão de custos dentro da organização. Destaca-se a recorrência das seguintes atribuições: "análise da variação de custos", "monitoramento e preparação de relatórios", "parametrizar e contabilizar estoques", "cálculo da desvalorização do estoque", "preparação de planilhas de budget", "acompanhar o consumo de matéria-prima", "analisar a relação entre o que foi efetivamente gasto e o orçado", "atuar na consolidação das informações de vendas e compras", "elaborar e analisar planilhas de depreciação e amortização", "calcular e analisar os custos do transfer prince", "apoiar o planejamento, preparação e consolidação", "realizar a auditora de custos nos departamentos", "atuar com impostos, créditos de impostos, substituição tributária”, "fechar estoque e análise de resultado. Apropriar de despesas administrativas e industriais", "atuar com rotinas de inventário rotativo e periódico", "criar e elaborar relatórios gerenciais" e "irá liderar o processo de previsão orçamentária”.
Figura 2 - Nuvem de palavras dos termos mais utilizados para descrever as atribuições do cargo

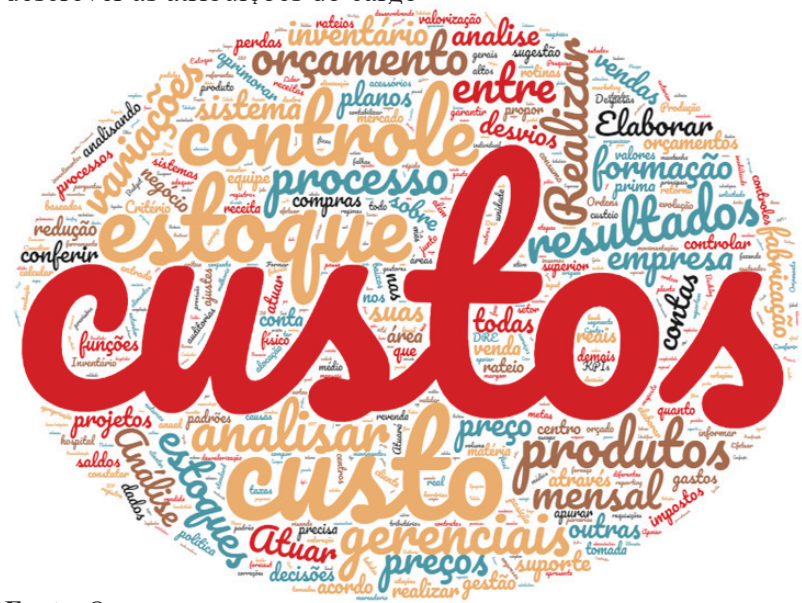

Fonte: Os autores.

Ao analisar uma informação por meio da nuvem de palavras se percebe que quanto mais as palavras são repetidas ao longo do texto informado, maior é sua importância. Considerando a imagem acima se conclui que os termos: custos, controle, estoques, orçamento, projetos e análise são os mais repetidos na descrição das atribuições dos profissionais.

No Quadro 6 constam os requisitos específicos de cada vaga de emprego, analisando esses dados se permite conhecer quais são as expectativas que as organizações possuem ao contratar novos profissionais para seus departamentos de custos. A primeira informação que pode ser analisada retrata a expectativa que as empresas possuem em relação à experiência anterior dos novos contratos, de todos os 63 anúncios analisados 39 consideram haver a necessidade de experiência anterior, ou seja, $61,9 \%$ das empresas necessitam de profissionais que já tenham trabalhado com: gestão de custos, elaboração de orçamentos, controladoria, análise dos efeitos da variação do patrimônio, contabilidade, análise e elaboração de indicadores econômicos e financeiros e precificação.

Quadro 6 - Principais conhecimentos prévios solicitados pelas empresas contratantes

\begin{tabular}{|c|c|c|}
\hline Conhecimento & Vagas & Especificação \\
\hline \multirow{7}{*}{$\begin{array}{l}\text { Experiência } \\
\text { anterior }\end{array}$} & \multirow{7}{*}{$\begin{array}{c}39 \\
\text { vagas }\end{array}$} & Gestão de custos \\
\hline & & Elaboração de orçamentos \\
\hline & & Controladoria \\
\hline & & $\begin{array}{l}\text { Análise dos efeitos da variação no } \\
\text { patrimônio }\end{array}$ \\
\hline & & Contabilidade \\
\hline & & $\begin{array}{l}\text { Análise de indicadores econômicos } \\
\text { financeiros }\end{array}$ \\
\hline & & Precificação \\
\hline \multirow{4}{*}{ Softwares } & \multirow{4}{*}{$\begin{array}{c}19 \\
\text { vagas }\end{array}$} & Excel \\
\hline & & Power point \\
\hline & & Access \\
\hline & & Office completo \\
\hline \multirow{6}{*}{$\begin{array}{c}\text { Softwares de } \\
\text { Gestão (ERP) }\end{array}$} & \multirow{6}{*}{$\begin{array}{c}21 \\
\text { vagas }\end{array}$} & Oracle \\
\hline & & B.I. \\
\hline & & SAP \\
\hline & & Protheus \\
\hline & & GATEC \\
\hline & & Totvs \\
\hline
\end{tabular}




\begin{tabular}{|c|c|l|}
\hline Conhecimento & Vagas & \multicolumn{1}{|c|}{ Especificação } \\
\hline \multirow{2}{*}{$\begin{array}{c}\text { Métodos } \\
\text { quantitativos }\end{array}$} & 9 & Matemática financeira \\
\cline { 3 - 3 } & vagas & Raciocínio Lógico \\
\cline { 3 - 3 } & & Estatística \\
\hline Outros & 1 vaga & Importação \\
\hline
\end{tabular}

Fonte: Dados da pesquisa.

Em relação ao conhecimento de software se constata que há grande procura por profissionais que saibam utilizar os pertencentes ao pacote Office da Microsoft, principalmente, o Excel, software de planilhas eletrônicas, um dos mais pedidos pelas empresas em seus processos de contratação. Considerando a grande popularização desse tipo de software nos ambientes corporativos se pode afirmar que desconhecer o seu uso, ou não possui certa familiaridade com o mesmo, pode impactar na busca por uma vaga de emprego nesta área.

No que concerne ao uso dos sistemas integrados de gestão empresarial, também conhecido como ERP, 33,3\% das empresas anseiam por profissionais que já possuem conhecimento sobre a utilização desses, sendo que os principais são: SAP, Oracle, Protheus, Totvs e GATEC.

As empresas ainda apresentam algumas necessidades particulares, entre essas se destaca o anúncio de uma vaga em que se necessitava de um profissional para trabalhar com gestão de custos, com especificação no processo de importação de mercadorias.

\section{Conclusão}

A busca por desenvolver uma vantagem competitiva diante de mercados globalizados e de alta concorrência, faz com que as empresas necessitem de profissionais multifacetados para o desenvolvimento das suas operações. Nem sempre o desenvolvimento de competências é possível entre os profissionais, que já trabalham nas organizações, em algumas oportunidades, como a necessidade de reposição ou espação do quadro de colaboradores se faz necessária a contratação e consequente busca de novos profissionais no mercado.

Ao anunciar as vagas em grandes portais da internet, as empresas acabam por abrir suas necessidades a todos, inclusive, aos seus concorrentes, muitas optam por realizar a contratação utilizando de intermediários como agências de recrutamento e de seleção evitando de terem suas informações expostas. De qualquer forma, ao anunciar vagas na internet, as empresas acabam por expor parte de sua estratégia de negócios.

Apreciando os resultados obtidos por meio da metodologia empregada visando a resposta à pergunta de pesquisa pretendida, conclui se que as organizações, que buscam profissionais de custos para ingressar em seu quadro de colaboradores, procuram profissionais preferencialmente formados em Ciências Contábeis e Administração, que possuam Pós-graduação, que falem uma segunda língua, e que possuam experiência anterior na gestão de custos. Ainda, compõe o perfil do profissional de custos aquele que possui domínio do pacote Office da Microsoft, em especial do Excel, e também conhecimento sobre sistemas de gestão como os ERP's.

Como proposta de estudos futuros fica a sugestão de que essa mesma pesquisa seja aplicada considerando um maior recorte temporal e se espera que com isso um maior número de vagas possa ser analisado validando os dados aqui apresentados, ou ao menos, complementando-os.

\section{Referências}

ALENCAR, R.C; GUERREIRO, R. A mensuração do resultado da qualidade em empresas brasileiras. Rev. Contab Finanç. v.15, p.7-23, 2004. doi: https://doi.org/10.1590/S151970772004000400001 .

BARBOSA, A.C.Q. Gestão de Competências: da experiência organizacional à proposta setorial e/ou por categorias profissionais - um estudo de modelos no Brasil. In: ENCONTRO DAANPAD, 32, 2008, Rio de Janeiro. Anais... Rio de Janeiro: EnANPAD, 2008.

BARDIN, L. Análise de conteúdo. Lisboa: Edições 70, 1997.

BARROS, L.E.V.; PAIVA, K.C.M.; CAPPELLE, M.C.A. Managerial competences and their management: a study in brazilian inns of a historic city - Tiradentes, Minas Gerais. Tourism \& Management Studies, v.13, n.2, p.71-82. doi: $10.18089 /$ tms.2017.13207

BERND, D. C.; ANZILAGO, M.; MACHADO, R. F. Demanda de Profissionais de Custos no mercado de trabalho no Paraná. In: CONGRESSO BRASILEIRO DE CUSTOS, 21, 2014, Natal RN. Anais... Natal: Congresso Brasileiro de Custos, 2014.

BEUREN, I.M.; SCHAEFFER, V. Análise dos custos do ciclo de vida do produto: uma abordagem teórica. In: ENCONTRO NACIONAL DE ENGENHARIA DE PRODUÇÃO - ENEGEP, 17, 1997.

BOWMAN, E.H. et al. The domain of strategic management: history and evolution. In: PETTIGREW, A. et al. Handbook of strategy e management. Londres: Sage Publications, 2001.

BRITO, R.P.; BRITO, L.A. L. Vantagem competitiva e sua relação com o desempenho: uma abordagem baseada em valor. $R A C$, v.16, n.3, p.360-380, 2012.

CAVALCANTE, G.M.;AMORIM, T.N.G.F.Análise das principais competências exigidas dos profissionais de contabilidade nas instituições públicas: um levantamento realizado no Instituto Federal de Educação, Ciências e Tecnologia de Alagoas (IFAL). In: CONGRESSO UFPE DE CIÊNCIAS CONTÁBEIS. Disponível em $<$ https://periodicos.ufpe.br/revistas/SUCC/article/ download/22783/19547> Acesso em: 1 maio 2020.

CALIJURI, M.S.S. Controller: o perfil atual e a necessidade do mercado de trabalho. Rev. Bras. Contab., n.150, p.37-52, 2011.

CHAKRAVARTHY, B.S.; WHITE, R.E. Strategy process: forming, implementing and changing strategies. In: PETTIGREW, A. et al. Handbook of strategy e management. Londres: Sage Publications, 2001

DUTRA, C.A.F. A contribuição da gestão por competências para uma administração escolar participativa: um estudo de caso. Adm. Emp. Rev., v.17, n.18, p.68-82, 2007. doi: 10.6084/ m9.figshare.5417509.

DUTRA, J.S; HIPOLITO, J.M; SILVA, C.M. Gestão de pessoas por competências: o caso de uma empresa do setor de telecomunicações. Rev. Adm. Contemp., v.4, n.1, p.161-176, 2000 doi: https://doi.org/10.1590/S1415-65552000000100009.

FLEURY, M.T.L. A gestão de competências e a estratégia 
organizacional. As pessoas na organização. São Paulo: Gente. 2002.

GOMES, C.V.; SOUZA, P.; LUNKES, R.J. O perfil do profissional da controladoria solicitado por empresas brasileiras. Rev. Global. Competitiv. Governabil. v.8. n.1, p.34-50. doi 10.3232/GCG.2014

GRANLUND, M.; TAIPALEENMÂKI, J. Management control and controllership in new economy firms - a life cycle perspective. Manag. Accounting Res., v.16 n., p.21-57, 2005. doi:10.1016/j.mar.2004.09.003

GUILDING, C.; CRAVENS, K.S.; TAYLES, M. An international comparison of strategic management accounting practices. Manag. Account. Res., n.11, p.113-135, 2000. doi: https://doi. org/10.1006/mare.1999.0120

HARTMANN, F.G.; MASS, V.S. Why business unit controllers create budget slack: involvement in management, social pressure, and Machiavellianism. Behavioral Res. Inaccounting, v.22, n.2, p.27-49, 2010. doi: https://hdl.handle.net/11245/1.332817

JOHNSON, G. et al. Fundamentos de estratégia. Porto Alegre: Bookman, 2011.

LAMES, E.R.; ALMEIDA, F.S. Um estudo sobre as competências do contador versus perfil desejado pelas empresas sob a ótica dos futuros profissionais da área. In: CONGRESSO BRASILEIRO DE CUSTOS, 16, 2009, Fortaleza - CE. Anais... Fortaleza: Congresso Brasileiro de Custos, 2009.

LAUSCHNER, M. A.; BEUREN, M. A. Gestão estratégica de custos. Rev. Contab. Vista Rev., v.15, n 2, p.53-84, 2004.

LÓPEZ, J.; IBARRA, F. El análisis de costes en la contabilidad de dirección estratégica. In: SÁNCHEZ, J. (Coord.). Avances y prácticas empresariales en contabilidad de gestión. Madris: AECA, 1996. p.315-341.

MARCONI, M.A.; LAKATOS, E.M. Metodologia cientifica. São Paulo: Atlas, 2017.

MARTINS, G.A.; THEOPHILO, C.R. Investigação cientifica para ciências sociais aplicadas. São Paulo: Atlas, 2009.

McCLELLAND, D. C. Testing for Competence Rather Than for "Intelligence". Am. Psychol., v.28, n.1, 1973. doi: https://doi. org/10.1037/h0034092

MINTZBERG, H. et al. Safari de estratégia. Porto Alegre: Bookman, 2010.

NAKATA, L.E.; SOUSA, E.G. O conceito de competências e sua aplicação na gestão estratégica de pessoas nas empresas atuantes no Brasil. Rev. Econ. Gestão, v. 12, n. 29, 2012.

QUESADO, P.R.; RODRIGUES, L.L. A gestão estratégica de custos em grandes empresas portuguesas. Rev. Iberoam. Contab. Gestión, v.5, n.10, p.1-15, 2007.

PORTER, M. E. What is Strategy? Harvard Bus. Rev., v.74, n 6, p 61-78, 1985.

PUPO, G.A.R.; MARTIN, L.A.G. Dynamics of the evolution of the strategy concept 1962-2008: a co-word analysis. Strategic
Manag. J., v.33, p.162-188, 2012. Doi; https://doi.org/10.1002/ smj.948

REIS, A.O. et al. Perfil do Profissional Contábil: Habilidades, Competências e Imagem Simbólica. Rev. Contemp. Contabil., v.12, n.25, p.95-116. 2015. doi: http://dx.doi.org/10.5007/21758069.2015v12n25p95

ROCHA, W. Gestão Estratégica. In: CONGRESSO BRASILEIRO DE CUSTOS, 6, 1999, São Paulo, Anais.

ROCHA, G.B.; PASSADOR, C.S.; SHINYASHIKI, G.T. What is the social gain from competency management? The employees' perception at a Brazilian public university. Rev. Adm., v.52, n.3, p.233-245, 2017. doi: .https://doi.org/10.1016/j. rausp.2017.05.001.

SAMPIERI, R.H.; COLLADO, C.F.; LUCIO, M.P.B. Metodologia de pesquisa. São Paulo: Mc Graw Hill, 2013.

SHANK, J. K.; GOVINDARAJAN, V. A revolução dos custos: como reinventar e redefinir sua estratégia de custos para vencer em mercados crescentemente competitivos. Rio de Janeiro: Campus, 1995.

SLAVOV, T.N.B. Gestão estratégica de custos: uma contribuição para construção de sua estrutura conceitual. São Paulo: USP, 2013.

SOUSA, B.C.; BORINELLI, M. L. As funções de controladoria: um estudo a luz dos anúncios das empresas de recrutamento de profissionais. In: CONGRESSO BRASILEIRO DE CUSTOS, 16, 2009, Fortaleza - CE. Anais... Fortaleza: Congresso Brasileiro de Custos, 2009.

SOUZA, M.A.; SILVA, E.J.; PILZ, N. Práticas de gestão estratégica de custos: um estudo em uma empresa multinacional brasileira. RCO, v.4, n.9, p.145-167, 2010. doi: https://doi. org/10.11606/rco.v4i9.34771

TRIVINOS, A.N.S. Introdução à pesquisa em ciências sociais: a pesquisa qualitativa em educação. São Paulo: Atlas, 2012.

VASCONCELOS, F.C.; BRITO, L.A.L. Vantagem competitiva: o construto e a métrica. $R A E$, v.44, n.2, p.51-63, 2004. doi: http:// dx.doi.org/10.1590/S0034-75902004000200006

WEBER, J. The development of controller tasks: explaining the nature of controllership and its changes. J. Manag. Control,, v.22, p.25-46, 2011. doi: https://doi.org/10.1007/s00187-011-0123-x

WITTMANN, G. et al. Caracterizando a gestão estratégica de custos na busca de vantagem competitiva. In: CONGRESSO BRASILEIRO DE CUSTOS, 19, 2012, Bento Gonçalves-RS, Anais.

ZONI, L.; MERCHANT, K. A. Controller involvement in management: an empirical study in large Italian corporation. $J$. Account. Organiz. Change, v.3, n.1, p.29-43, 2007.

ZORN, D.M. Here a chief, there a chief: the rise of the cfo in the american firm. Am. Sociol. Rev., v.69, n.3, p.345-364, 2004. doi: http://dx.doi.org/10.1177/000312240406900302 . 